\title{
Unusual Presentation of Localized Gastric Mucosa-Associated Lymphoid Tissue Lymphoma Mimicking Poorly Differentiated Gastric Adenocarcinoma
}

\author{
Yutaka Tomizawa $^{a}$ Michiharu Seki $^{\mathrm{b}}$ Masaya Mori ${ }^{\mathrm{c}}$ \\ ${ }^{a}$ Department of Internal Medicine, University of Pittsburgh Medical Center, \\ Presbyterian Shadyside, Pittsburgh, Pa., USA; ${ }^{b}$ Department of Internal \\ Medicine, Division of Gastroenterology and Hepatology, and ' Department of \\ Pathology, Mitsui Memorial Hospital, Tokyo, Japan
}

\section{Key Words}

Mucosa-associated lymphoid tissue lymphoma - Poorly differentiated gastric adenocarcinoma $\cdot$ Centrocyte-like cell $\cdot$ Lymphoepithelial lesion

\begin{abstract}
The risk of misdiagnosing neoplastic cells typically infiltrating an epithelium forming a lymphoepithelial lesion as poorly differentiated gastric cancer in endoscopic biopsies, particularly in low-grade mucosa-associated lymphoid tissue (MALT) lymphomas, is described. A 76-year-old woman was referred for management of a poorly differentiated gastric adenocarcinoma. Diagnostic endoscopy in our unit showed a $2 \mathrm{~cm}$ raised, submucosal lesion with central erosion in the upper body of the stomach, but repeat biopsies of the lesion were interpreted as inflamed gastric mucosa and negative for malignancy. Systematic gastric biopsies to rule out any foci of MALT lymphoma changes were also negative. Therefore, endoscopic submucosal dissection was performed to obtain an accurate specimen. Histology revealed centrocyte-like cells and a lymphoepithelial lesion invading into the mucosa with obliteration of the gastric glands, which was initially interpreted as poorly differentiated adenocarcinoma.
\end{abstract}




\section{Introduction}

The gastrointestinal tract is the predominant site of extranodal non-Hodgkin lymphomas. Primary non-Hodgkin lymphomas of the gastrointestinal tract are rare, accounting for only 1-4\% of malignancies arising in the stomach, small intestine or colon. Gastric lymphoma is the most common extranodal site of lymphoma. Mucosa-associated lymphoid tissue (MALT) lymphoma comprises 7-8\% of all B-cell lymphomas and at least $50 \%$ of primary gastric lymphomas [1]. It reaches its peak incidence between the ages of 50 and 60 years and there is a slight male predominance. Patients with gastric MALT lymphoma typically present with nonspecific symptoms such as nausea, vomit, non-ulcer dyspepsia, epigastric discomfort, anorexia, weight loss, or occult gastrointestinal bleeding. Physical examination is often normal, but may reveal a palpable mass or peripheral lymphadenopathy when the disease is advanced. Laboratory studies also tend to be normal at presentation and anemia may be present in selected cases. The diagnosis should be confirmed by biopsy. Findings on upper endoscopy are diverse, including mucosal erythema, benign-appearing gastric ulcer or nodular lesion. Multiple biopsies should be obtained from both suspicious-appearing lesions and normal-appearing mucosa in the stomach since gastric MALT lymphoma can occasionally present as multifocal disease with involvement of tissue that appears to be unaffected on initial visualization. Conventional pinch biopsies may miss the diagnosis, since gastric MALT lymphoma can infiltrate the submucosa without affecting the mucosa. This problem is most likely to occur when no obvious mass is present. We should aim to attain the largest biopsy specimen possible. In epithelial tissues, MALT lymphomas are composed of morphologically heterogeneous small B-cells including marginal zone (centrocyte-like) cells, monocytoid cells, and small lymphocytes. The neoplastic cells typically infiltrate the epithelium forming a lymphoepithelial lesion (LEL) [2]. The risk of misdiagnosing such lesions as poorly differentiated gastric cancer in endoscopic biopsies, particularly in low-grade MALT lymphomas in which LEL may be particularly abundant, is well described [3].

\section{Case Report}

A 76-year-old woman was referred for the management of poorly differentiated gastric adenocarcinoma diagnosed at the time of a routine screening upper endoscopy. She had been otherwise healthy and denied any recent anorexia or weight loss. Her past medical history was unremarkable and family history showed that her father had gastric cancer. Physical examination at presentation did not show any abdominal mass or palpable lymphadenopathy. Laboratory evaluation was likewise unrevealing. A diagnostic upper endoscopy in our unit revealed a $2 \mathrm{~cm}$ raised, submucosal lesion with central erosion in the upper body of the stomach ( $\underline{\text { fig. } 1}$ ). Repeat biopsies of the lesion were interpreted as inflamed gastric mucosa with positive Helicobacter pylori. We also performed systematic gastric biopsies to rule out any foci of MALT lymphoma changes within the stomach, however the results were not significant. Computed tomography of the chest and abdomen was negative for any lymphadenopathy or distant metastases. Based on the localized endoscopic findings and repeat negative biopsy results, we performed an endoscopic submucosal dissection (ESD) for diagnostic therapy. The resected specimen revealed a white, elastic, nodular, submucosal mass. Histological study revealed a well-circumscribed lymph follicle containing large germinal centers in the submucosa invading the muscularis mucosa and mucosa ( $\underline{\text { fig. } 2}$ ). Centrocyte-like cells and epitheliotropic proliferation (LEL) invading into the mucosa with obliteration of the gastric glands ( $\underline{\text { fig. } 3}$ ) were also seen. While the LEL was initially interpreted as poorly differentiated adenocarcinoma, the pathological evidence obtained from ESD established the diagnosis of a MALT 
lymphoma of the stomach (c-stage IE). After eradication of $H$. pylori with antibiotics, the patient has had no local or distant recurrences during the subsequent 2 years of surveillance follow-up.

\section{Discussion}

The World Health Organization (WHO)/Revised European American Lymphoma (REAL) classification scheme groups all lymphomas involving extranodal sites (gastrointestinal tract, thyroid, lung, breast, orbit and skin) into the category of MALT lymphomas [4]. Although patients with gastric MALT lymphoma often present with stage I or II extranodal disease, those patients may have vastly different presentations depending on its size and location: asymptomatic, gastric outlet obstruction, or weight loss. Adding to the diagnostic challenge, there are no characteristic endoscopic findings [5]. Gastric MALT lymphoma often presents as multifocal disease within the stomach and systematic gastric biopsy is crucial for diagnosis. In this localized MALT lymphoma case, theoretically, since gastric MALT lymphomas develop from mucosa-associated lymphoid tissue, ESD should be adequate to obtain lymphoma tissue for the definite diagnosis.

A previous study showed an association between previous $H$. pylori infection and the development of gastric MALT lymphoma and that eradication of $H$. pylori with antibiotics results in regression of gastric MALT lymphomas [6,7]. This finding has been confirmed by others [8-10]. As gastric MALT lymphoma is classified as an indolent non-Hodgkin lymphoma, stable asymptomatic patients with persistently positive biopsies have been successfully followed until disease progression.

In conclusion, we report a case of localized gastric MALT lymphoma diagnosed by ESD. ESD is a reasonable option for the diagnosis of localized gastric MALT lymphomas in selected cases in whom adequate tissue samples are difficult to obtain. 


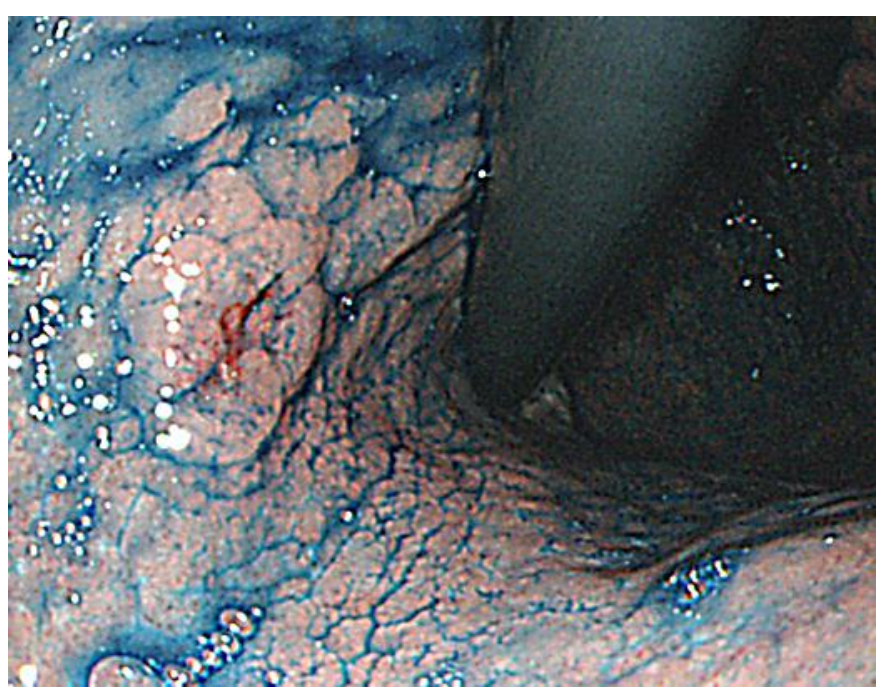

Fig. 1. Submucosal lesion of the stomach. $2 \mathrm{~cm}$ raised lesion with central erosion in the upper body of the stomach (indigo carmine stain).

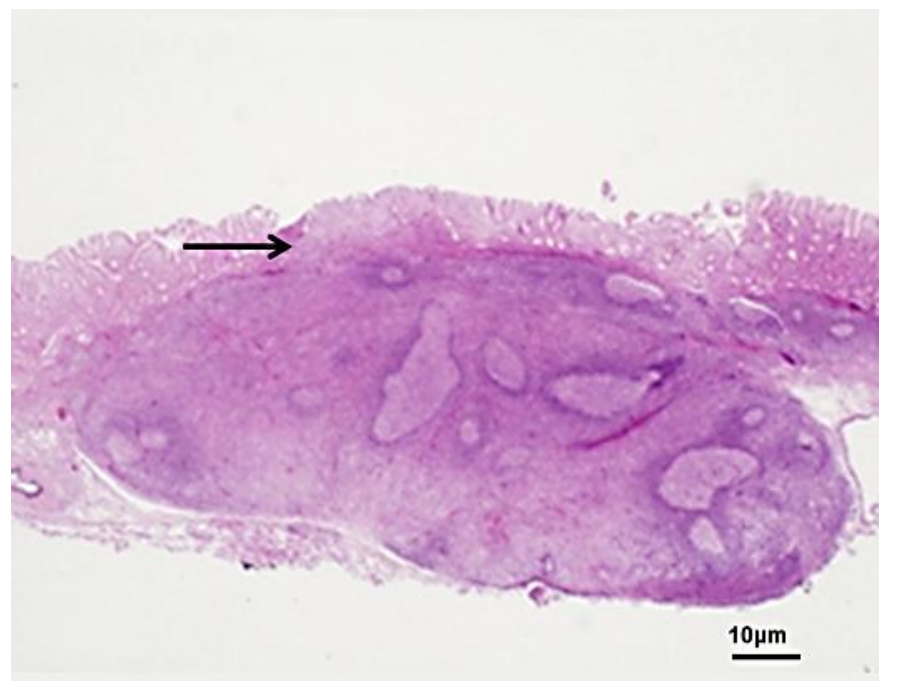

Fig. 2. Submucosal lymph node. Well-circumscribed submucosal lymph node invading the muscularis mucosa into the mucosa (H\&E stain, $\times 1.25)$. 


\begin{tabular}{|c|c|c|c|}
\hline $\begin{array}{l}\text { Case Reports in } \\
\text { Gastroenterolocy }\end{array}$ & $\begin{array}{l}\text { Case Rep Gastroenterol 2012;6:47-51 } \\
\text { DOI: 10.1159/000336322 }\end{array}$ & $\begin{array}{l}\text { Published online: } \\
\text { January 25, } 2012\end{array}$ & $\begin{array}{l}\text { (c) } 2012 \text { S. Karger AG, Basel } \\
\text { ISSN } 1662-0631 \\
\text { www.karger.com/crg }\end{array}$ \\
\hline
\end{tabular}

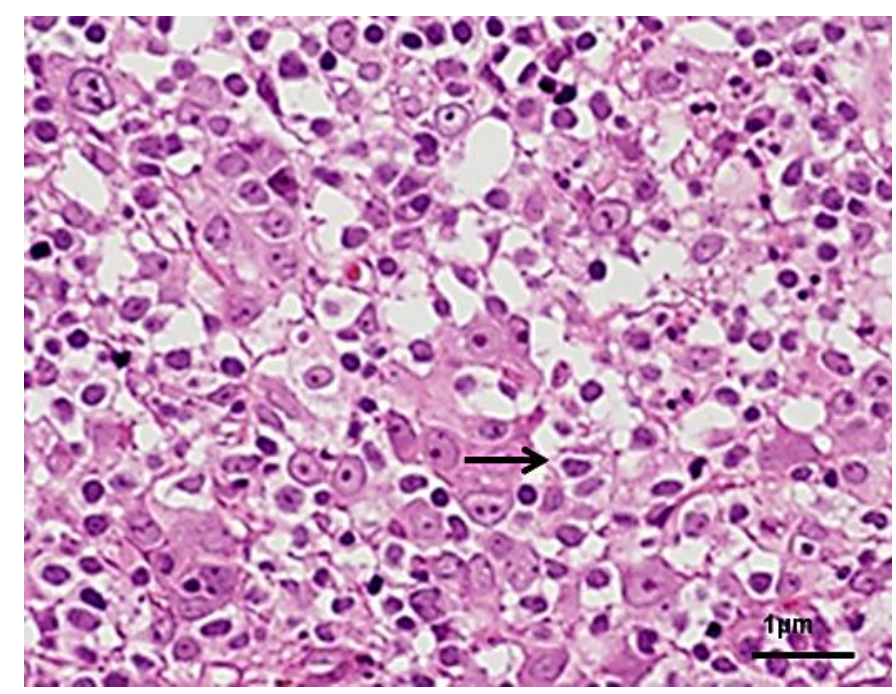

Fig. 3. LEL resembling poorly differentiated adenocarcinoma (H\&E stain, $\times 40)$.

\section{References}

1 Fischbach W, Kestel W, Kirchner T, Mössner J, Wilms K: Malignant lymphomas of the upper gastrointestinal tract. Results of a prospective study in 103 patients. Cancer 1992;70:1075-1080.

-2 Isaacson P, Wright DH: Extranodal malignant lymphoma arising from mucosa-associated lymphoid tissue. Cancer 1984;53:2515-2524.

-3 Zamboni G, Franzin G, Scarpa A, et al: Carcinoma-like signet-ring cells in gastric mucosa-associated lymphoid tissue (MALT) lymphoma. Am J Surg Pathol 1996;20:588-598.

4 Harris NL, Jaffe ES, Diebold J, et al: Lymphoma classification - from controversy to consensus: the R.E.A.L. and WHO Classification of lymphoid neoplasms. Ann Oncol 2000;11(suppl 1):3-10.

$\checkmark 5$ Zullo A, Hassan C, Andriani A, et al: Primary low-grade and high-grade gastric MALT-lymphoma presentation: a systematic review. J Clin Gastroenterol 2010;44:340-344.

-6 Wotherspoon AC, Ortiz-Hidalgo C, Falzon MR, et al: Helicobacter pylori-associated gastritis and primary B-cell gastric lymphoma. Lancet 1991;338:1175-1176.

7 Wotherspoon AC, Doglioni C, Diss TC, et al: Regression of primary low-grade B-cell gastric lymphoma of mucosa-associated lymphoid tissue type after eradication of Helicobacter pylori. Lancet 1993;342: 575-577.

8 Roggero E, Zucca E, Pinotti G, et al: Eradication of Helicobacter pylori infection in primary low-grade gastric lymphoma of mucosa-associated lymphoid tissue. Ann Intern Med 1995;122:767-769.

-9 Neubauer A, Thiede C, Morgner A, et al: Cure of Helicobacter pylori infection and duration of remission of low-grade gastric mucosa-associated lymphoid tissue lymphoma. J Natl Cancer Inst 1997;89:1350-1355.

10 Steinbach G, Ford R, Glober G, et al: Antibiotic treatment of gastric lymphoma of mucosa-associated lymphoid tissue. An uncontrolled trial. Ann Intern Med 1999;131:88-95. 